\title{
CIDADES COMPLEXAS NO SÉCULO XXI ciência, técnica e arte
}

\author{
Maria Margarida Cavalcanti Limena \\ Professora do Departamento de Sociologia e Membro do Núcleo de Estudos da Complexidade da PUC-SP
}

\begin{abstract}
Resumo: A discussão sobre o futuro das metrópoles contemporâneas realizada neste artigo parte do pressuposto de que as crises urbanas não podem ser pensadas como resultado de um processo linear ou determinado, mas como processo complexo, que requer uma visão macroscópica, visando à identificação de seus atributos, suas tendências, contratendências, determinações e indeterminações. Propõe formas de compreensão pautadas por uma ampliação dos operadores cognitivos, estabelecendo o diálogo interdisciplinar que busca superar os limites entre ciência, técnica e arte.

Palavras-chave: urbanismo; imaginário urbano; complexidade; interdisciplinaridade.
\end{abstract}

\begin{abstract}
A condição urbana baseia-se na coexistência de oposições e uma só imaginação não basta para integrar as verdadeiras contradições.
\end{abstract}

Rem Koolhaas

Desenhar a cidade dos sonhos é fácil; reconstruir a vida requer imaginação.

Jane Jacobs

$\Delta$ valiando-se o quadro geral das cidades atuais em que os problemas se acumulam em velocidade sempre superior às possibilidades de solução -, algumas questões impõem-se à reflexão: o modelo de cidade moderna, ou pós-moderna, responde às exigências impostas pelo mundo nesta entrada de milênio? O pensamento sobre as cidades, que repousa nos princípios herdados do racionalismo, ainda consegue responder à necessidade de garantir o planejamento e os projetos de sistemas complexos como a cidade e o território? Será que os valores implícitos nesse paradigma ainda são compatíveis com as grandes transformações em curso, como o movimento de desterritorialização, novos princípios de organização do espaço baseados na idéia de fluxos - de matéria, de mercadorias, de capitais, de pessoas, de bens, de informações? Como pensar e projetar o futuro, de forma a garantir que a realidade urbana possa ser vivida como experiência humana, individual e coletiva?
Fornecer respostas a estas questões implica a construção de outras formas de compreensão da cidade e do fenômeno urbano, como parte integrante de um projeto de sociedade planetária, estabelecendo um diálogo interdisciplinar que busque interconexões e possa constituir as bases para um saber menos restritivo e redutor. Nessa perspectiva, as crises urbanas não podem ser pensadas como resultado de um processo linear ou determinado, mas como um processo complexo, que requer uma visão macroscópica, capaz de identificar seus atributos, suas tendências, contratendências, determinações e indeterminações.

É certo que a escolha de futuros possíveis é extremamente ampla e variada. Cada opção pode nos parecer como um espelho de nossas esperanças e desejos de ambientes mais humanizados. Marshall McLuhan sugeriu, em 1960, que o mundo inteiro iria se tornar, um dia, uma "aldeia global", na qual todos os membros da humanidade poderiam interagir num simulacro em tempo real de uma comunidade neolítica. Passados 40 anos, a presença das assim chamadas comunidades virtuais expressa, de certo modo, a realização dessa profecia. Movimentos ambientalistas preconizam o "retorno à natureza", por meio do estabelecimento de comunidades rurais às margens da civilização urbanizada, enquanto outros movimentos também têm pregado os kibbutzen urbanos, localizados no coração de grandes cidades como Londres, Paris e Nova York. 
As imagens do futuro tecnológico apresentadas pela literatura e pelos filmes têm como motor uma visão pósapocalíptica da sociedade industrial e das grandes cidades, sugerindo perspectivas pouco promissoras para as cidades contemporâneas. De fato, artistas, poetas, romancistas e filósofos, contrapondo-se ao entusiasmo que permeia propostas e intervenções deliberadamente produzidas a partir de princípios de organização técnico-racional, expressam sua preocupação com um futuro utópico baseado não em experiências compartilhadas, mas no conhecimento técnico e seus efeitos em relação às diferentes formas de poder - administrativo, legal e físico -, que se desdobram em imagens de governos repressivos, sociedades violentas, lugares desagradáveis, perda de referências para a identidade pessoal, indivíduos que cumprem rotinas, mas que se saciam nos prazeres materiais.

Essa mesma visão também constitui a base para diagnósticos pessimistas sobre o devir das cidades, que se expressam na falta de esperanças quanto a um futuro que possa tornar viáveis espaços urbanos para cidadãos e que possa reverter na melhoria da qualidade de vida, entendida na plenitude dos enraizamentos biopsicoantropossociais do homem.

Lewis Mumford construiu a metáfora da cidade como "megamáquina moderna" para expressar suas preocupações sobre as tendências observadas em cidades baseadas no desenvolvimento de um sistema de gestão e administração "maquinal": "é uma máquina enorme e irracional que ordena, organiza e controla tudo o que pode [...] como o Pentágono, a megamáquina é insensível à informação, especialmente a informação da qualidade, que não é compatível com o seu sistema e atrai especialistas, poder e dinheiro para fins que ultrapassam os limites da razão humana. Só tem uma velocidade de funcionamento - mais rápido; só um destino atrativo - mais longe; só um tamanho desejável - maior; só um objetivo racional - mais" (Mumford apud Relph, 1990:120-21).

A escala e complexidade da paisagem propiciada por essa megamáquina moderna podem ser percebidas em seus produtos, que incluem arranha-céus, reatores atômicos, terrenos suburbanos sendo ocupados crescentemente, centros comerciais, aeroportos internacionais, parques, shopping centers e tudo o mais que compõe a paisagem contemporânea. Aquilo que deveria ser evidente não é, ou seja, em tal escala e complexidade, tudo o que a compõe depende e resulta de conhecimentos técnicos e de níveis de organização sofisticados. De fato, essa percepção parece não ser imediata, quer porque a preocupação maior esteja voltada à paisagem em si e não às suas origens, quer porque estejamos alienados com as ilusões "imaginhadas", conforme observa Edward Relph. ${ }^{1}$

Outras visões, denominadas tecno-otimistas, compartilhadas por autores como Mike Davis (1993), Alan Jacobs e Donald Appleyard (1996), dentre outros, para os quais a tecnologia é pressuposto básico para a melhoria das condições de vida urbana, fornecem recursos para pensar os problemas, a integridade e a viabilidade do futuro dos grandes centros urbanos. Encaminham propostas que remetem a paisagens nas quais à tecnologia agregam-se arquitetura, design, preservação do patrimônio histórico, nobilitação comercial, residencial e planejamento comunitário. Ambas as perspectivas têm fornecido propostas e alternativas para as cidades do amanhã, que oscilam entre o combate e a necessidade de tomar partido das tendências apontadas pelo presente, marcadas pela proliferação de parques temáticos, de experiências urbanas que tendem ao isolamento de grupos, como os condomínios fechados, dos hotéis, aeroportos e shopping centers.

Freqüentemente, ao tecno-otimismo opõe-se o tecnopessimismo, lançando prognósticos sombrios baseados na paisagem inóspita e na falta de identidade com os lugares, na perda de autonomia dos indivíduos, presentes em filmes de ficção científica e histórias em quadrinhos. Podese pensar, entretanto, que utilizados em relação de complementaridade, esses termos, relacionados a princípios que operam em níveis distintos, possam contribuir para a construção de um olhar sobre a cidade capaz de captar não apenas suas dimensões objetivas - estrutural, funcional, histórica - mas também subjetivas, referentes a aspectos do inconsciente coletivo que muitas vezes analistas e pesquisadores não conseguem perceber, fornecendo condições para interrogarmos o presente e projetarmos o futuro.

Edificadas a partir de princípios universais, presentes num mundo unificado sob o signo da ciência, nossas cidades, e especialmente as grandes metrópoles, ostentam as marcas daquilo que Ramonet denominou "pensamento único" (1995), definindo-o como "a transposição, em termos ideológicos - que se pretendem universais -, de interesses de um conjunto de forças econômicas e, especificamente, daquelas ligadas ao capital internacional", cujo caráter é restritivo: o econômico prevalece sobre o político, vivencial e simbólico. Sob esse princípio, a par da crise em que se encontram as diversas áreas do conhecimento, em que prevalecem as idéias de ordem, regularidade, previsão, controle, otimização, também se encontram exau- 
ridos muitos dos conceitos e operadores por meio dos quais as cidades têm sido pensadas, como o planejamento, standardização, técnicas de previsão, tendendo a uma visão reducionista e mecanicista. Torna-se cada vez mais difícil sustentar, nos dias que correm, a idéia de que é possível prever a evolução da cidade a partir de leis simples e regulares.

Dada a complexidade das cidades contemporâneas, não é mais possível imaginar, também, que a intervenção em uma parte da cidade não afete o todo ou que os efeitos produzidos por causas diversas possam ser somados segundo procedimentos lineares. Nessa mesma perspectiva, a perda de eficácia desses conceitos e procedimentos pode ser melhor observada quando as cidades são referidas a partir de seus habitantes, em termos de atendimento de suas necessidades materiais e imateriais.

Não obstante, a preocupação maior dos urbanistas, planejadores e administradores tem se voltado à cidade e ao território físico, quase como um "indistinto geométrico" (Scandurra, 1998:92-103), a ser ocupado e otimizado; trabalhando, na maior parte dos casos, com evidências empíricas, suas propostas de ocupação, ordenamento, revitalização ou reorganização dos espaços urbanos não alcançam aspectos essenciais que dizem respeito à forma pela qual os habitantes de uma cidade vivem, percebem e imaginam o espaço em que constroem suas vidas. Do mesmo modo, planejadores e administradores ainda orientam suas políticas de intervenção por princípios enunciados há quase um século, pautados por um pensamento contaminado pela ênfase nos negócios e pela ausência de objetivos sociais e políticos que possam reverter na melhoria das condições de vida para a totalidade dos cidadãos.

A despeito de haver uma infinidade de estudos da desordem e da decadência das cidades, lançando prognósticos para seu devir, os poucos que apontam na direção de melhorar as condições urbanas e fixar normas para seu crescimento e desenvolvimento prendem-se a visões inocentemente utópicas: de um lado, porque suas bases repousam na crença sem reservas dos dúbios imperativos de uma economia sempre em expansão; de outro, por atribuírem à técnica e à ciência importância máxima e suficiência em relação ao futuro da cidade, como se ambas pudessem, por si, fornecer os instrumentos necessários ao entendimento e à intervenção na cidade, em conjunto com os demais subsistemas que a compõem: tecnológicos, culturais, científicos, sociais e políticos.

Com freqüência, quando não secundários, são deixados de lado os aspectos relacionados a seus ritmos, signi- ficados e elementos estruturadores de uma identidade cosmopolita, que poderiam contribuir para alargar o conhecimento sobre a cidade. Prestar mais atenção à sensibilidade dos filósofos, artistas e literatos e de urbanistas que incorporam essa mesma sensibilidade talvez seja um bom caminho para a edificação de projetos urbanos capazes de articular ética e estética, não apenas em termos de um planejamento normativo, mas instaurativo, capaz de conduzir a outras formas de sociabilidade e remetendo-se ao "direito à cidade", tal como Henri Lefebvre (1991) definiu, em sua utopia urbana.

Tais questões estabelecem a necessidade de introdução de alguns elementos essenciais à compreensão das cidades, que têm sido tratados, freqüentemente, de modo fragmentário. Uma questão primordial diz respeito à forma de olhar a cidade que, longe de traduzir apenas imagens parciais, revela "qualificações" do espaço urbano. Além de desvelar o imaginário urbano presente em cada momento, um "olhar consciente" sobre a cidade permite a identificação da relação entre esta e o próprio pensamento, entre o público e o privado, entre os espaços da intimidade e os grandes espaços coletivos urbanos, entre a emergência de distintas formas de sociabilidade e os signos que as sustentam, recuperando algumas das prom essas de nossa cultura. "Se a cidade tem sido um locus de poder, cujos espaços tornaram-se coerentes e completos à imagem do próprio homem, também tem sido nela que essas imagens se estilhaçaram, no contexto de agrupamentos de pessoas diferentes - fator de intensificação da complexidade social - e que se apresentam umas às outras como estranhas", conforme aponta Richard Sennett (1997:24), ao procurar entender como os diversos aspectos da experiência urbana - em sua diferença, complexidade, estranheza - sustentam a sociabilidade humana em sua resistência à dominação. Considerando a cidade como "obra de arte" e não como mero artefato, Sennett (1990:170) acredita que impulsos para o desenvolvimento de um olhar consciente possam ser, igualmente, as fontes necessárias para a emergência e mobilização de energias criativas, tornando as pessoas visíveis e recuperando a plenitude dos sentidos.

Outro aspecto importante volta-se à necessidade de se reinserir nas análises da cidade a relação entre tempo e espaço, muitas vezes elidida. Na cidade moderna, a relação do caráter estético da unidade entre espaço e tempo e do caráter da sociedade tem sido marcadas pelo divórcio entre ambos, de acordo com a interpretação de Sennett (1990:170). Exemplificando, esse contraste foi a marca, 
no século XX, de projetos como aqueles de Mies Van der Rohe ou de Le Corbusier. Este último queria demonstrar a necessidade de liberdade de movimento em formas perfeitamente coordenadas, expressas no desenho racional das ruas e na fachada de seus edifícios, rejeitando a idéia de que nossas vidas não seriam, nem mais nem menos, uma continuidade ou adição ao passado.

Deve-se ressaltar que a revalorização das referências históricas locais, por meio da preservação do patrimônio e do retorno às raízes, tem fornecido paisagens urbanas que aparecem como unidade na diversidade, rompendo com as dualidades que situam a cidade entre a tradição e a modernidade ou, dito de outro modo, entre um passado bárbaro e um futuro prometedor, como na visão iluminista, ou ainda como a traição de um passado perfeito, de acordo com a visão antiindustrial. Vários projetos exemplificam a possibilidade de superação dessas dualidades, conciliando passado e presente, como o fenômeno da crescente ocupação de antigas cidadezinhas medievais que haviam sido abandonadas, especialmente na Itália e na França. Visando estabelecer condições para padrões mais elevados de qualidade de vida, profissionais liberais e artistas recuperaram essas formações, dotando as edificações de todos os requisitos necessários à vida moderna, dentre eles os meios de comunicação e conexão com os grandes centros urbanos, compatibilizando suas necessidades de trabalho com a simplicidade da vida no campo.

A revitalização de áreas históricas de Barcelona, Bolonha e Rio de Janeiro, bem como de quadriláteros em Manhattan como Grammercy Park e de ruas como Oxford Street em Londres ou, ainda, de quarteirões em Paris, recuperando exatamente atributos ligados à historicidade, também exemplifica a construção de propostas que tendem a chamar a atenção para a paisagem urbana como conjunto, como contexto formado por elementos múltiplos, fornecendo a possibilidade de leituras menos fragmentárias.

É importante, sem dúvida, recuperar a dimensão "antropológica" do espaço, relegada a um plano secundário, com o abuso da geometria euclidiana, segundo a qual as cidades passam a ser pensadas como espaço geometrizado, em que proliferam genealogias do território. Pierre Lévy (1995:22) chama a atenção para o fato de que, como espaço geometrizado, cada ponto é definido por um sistema de coordenadas, "um endereço, ainda que ninguém tenha lhe dado um nome. A história e o algoritmo têm lugar no sistema (do qual a Geografia científica representa evidentemente apenas um caso particular)". Com isso, a dimen- são "antropológica" coloca-se em plano secundário, como se os seres humanos habitassem, somente, um espaço físico ou geométrico e não afetivo, estético, social, histórico, em síntese, espaço de significações em geral.

Torna-se imperativo rever, também, a definição clássica de cidade com um centro, limites e periferia, a fim de se poder traçar as perspectivas para as cidades do futuro, a partir de dois argumentos centrais: o primeiro prendese a características presentes principalmente em grandes cidades e agrupamentos na Ásia e na África, mas também em algumas partes da Europa (mesmo prevalecendo a definição clássica de cidade), que se apresentam como um tecido urbano ininterrupto, no qual coexistem elementos rurais e urbanos, isto é, ausência de limites claros, o que impõe uma outra problemática. O segundo argumento prende-se à necessidade de se dar conta das novas formas de sociabilidade que nascem da sociedade em rede e já estimulam uma série de estudos acerca das comunidades e cidades virtuais.

A exposição Mutations, atualmente sendo realizada em Bordeaux, exemplifica a necessidade de introdução de novos elementos nos diagnósticos e prognósticos sobre a condição urbana da época. O discurso de Rem Kolhaas, ${ }^{2}$ uma das mais influentes expressões da arquitetura contemporânea, oscilando entre a retórica e o jogo da provocação, coloca os impasses do urbanismo diante de cidades contemporâneas instáveis e da presença de tecidos urbanos ininterruptos, nos quais não se percebem mais com clareza os limites entre rural e urbano. Quando projetou e construiu Euralille, o bairro francês concebido como um emaranhado de autopistas em torno de grandes edificações dedicadas ao comércio e ao transporte, ele chegou a identificar uma nova forma de urbanismo, cuja missão “já não seria dispor ordenadamente sobre o território objetos mais ou menos permanentes, senão colocar em cena a incerteza e o caos do momento".

Desse modo, o sentido da arquitetura não seria mais projetar e prever, mas tomar decisões estratégicas. É preciso entender bairros e áreas centrais, por exemplo, como um sistema dinâmico, com vários elementos em processo de interação e retroação. Assumindo a consciência dos efeitos e do grau de fiabilidade do sistema, os arquitetos deixariam de se levar pela evolução das cidades que ocorre independentemente deles, passando a fornecer instrumentos de reflexão sobre um novo fenômeno da paisagem urbana: a combinação de cityscape e landscape que deve se traduzir por um vocabulário capaz de descrever os fenômenos que circunscrevem novas situações híbridas. 
De sua experiência em cidades asiáticas veio o convencimento de que aquelas existentes no delta do Rio das Pérolas, na China, nas quais a diferença com o passado e a história da Europa não conta, representam a urbe do futuro. Se Paris foi a capital do século XIX e Nova York a do século XX, a capital do século XXI deverá se parecer com essa formação urbana, uma constelação formada por cerca de uma dúzia de cidades em que a principal é Shegzen, ao norte de Hong Kong. Contando hoje com cerca de 12 milhões de habitantes, prevê-se uma população, para 2020, de 36 milhões. É esse tipo de agrupamento que anuncia a cidade do século XXI, o que coloca em xeque a definição clássica de cidade com um centro, limites e periferia. Ao contrário, nesta nova forma de cidade terá desaparecido toda a idéia de centro e a densidade será completamente disseminada. Ele cita alguns exemplos: "já não haverá a necessidade de ter um metrô ao lado de arranha-céus, ou um arranha-céu ao lado de outro: a Internet e todas as formas de comunicação vão explodir e acabar com esse tipo de lógica. Poderemos ter uma povoação que tenha um arranha-céu de um lado e um campo de arroz do outro, sem que haja qualquer contradição entre estes elementos. São fenômenos que já se observam em certas cidades africanas, como Lagos, na Nigéria”.

$\mathrm{O}$ tipo de identidade que esses agrupamentos poderão permitir constitui aspecto relevante nas projeções de Kolhaas. Para ele, as referências locais clássicas desaparecerão, entrando em cena a cidade "genérica", que "será uma libertação, em comparação com identidades demasiado fortes e demasiado confinadas, em benefício de situações bastante mais vagas e portanto mais fáceis de controlar por aqueles que nelas habitam".

A instabilidade e a complexidade das novas formações urbanas não permitem mais que se possa conceber um plano urbano com configurações definitivas a serem mantidas durante 20 ou 30 anos, exigindo novas chaves para interpretação da arquitetura. Por outro lado, deve-se levar em consideração o fato de que nem os conhecimentos teóri$\cos$, nem os valores éticos transmitidos de uma geração a outra são adequados à interpretação e ao tratamento das grandes mutações urbanas ocasionadas por fenômenos de dimensões planetárias, como a economia de mercado, a informação, os conflitos bélicos, o que coloca a relação entre ética, estética e planejamento numa outra perspectiva de abordagem.

Não obstante, os planos para o futuro da cidade representam, na maior parte das vezes, não um programa de ação ou aquilo que a cidade gostaria de se tornar amanhã, mas um poderoso discurso para nos brindar com um futuro perfeito. Nesse sentido, o pensamento urbanístico e as análises sociológicas tendem a operar diretamente com uma visão ingênua do tempo. $\mathrm{O}$ recurso ao passado da cidade oferece elementos para a definição de problemas a serem solucionados, como uma espécie de catálogo, cujos elementos podem indicar uma rota de salvação. Isso posto, parece claro não existir concordância quanto ao passado da memória, ao presente descrito e narrado e ao futuro da imaginação e do planejamento. O passado existe como projeção daquilo que concerne ao presente e o desejo da boa cidade do futuro também existe na imaginação do passado. O futuro perfeito do discurso urbanístico volta-se a predições por meio de escolhas, por meio da representação do presente, expressa no desenho e na arquitetura da cidade. Dessa maneira, o reformismo urbanista não reconhece a densa complexidade do presente senão por meio da representação de desejos que já tenham sido realizados, projetando acontecimentos futuros não como algo desconhecido, mas como representação de um passado a ser recriado, ainda que se assentando em outras bases.

Politicamente, trabalhar desse modo com o desconhecido, isto é, buscando correlações de identidade ou uma substância que o articule às pessoas, aos cidadãos, à comunidade, é incompatível com uma imaginação radical democrática, que necessita da historicidade e da contingência para se exercitar na criação de significados. Assim, "o passado é uma projeção bem como uma determinação do presente; o futuro é menos um playground para especulações naturais que uma intimação à inventividade dentro de uma inextricável moldura repressiva" (Schorske, 2000:194). Nesse sentido, ainda que a imaginação necessária à construção e reconstrução de cidades seja produto de nossa tradição iluminista, temos de considerar que operamos numa temporalidade distinta. A definição do "agora" é fundamental para que estejamos inseridos na temporalidade presente, como forma de escapar às políticas que derivam de projeções autoritárias de princípios universais das cidades dos sonhos. Essa é, também, uma questão de liberdade, que consiste, tal como aponta Foucault, numa reflexão crítica sobre o presente.

Isso implica a necessidade de se enfatizar a multiplicidade de sentidos e significações que o mundo urbano oferece. A resposta possível ao futuro das grandes cidades dirige-se a uma questão fundamental em nossos dias: revitalizar o sentido das utopias, buscando as energias criativas das manifestações artísticas e retomando o caráter 
instaurativo das imagens urbanas como elemento fundamental. Em outros termos, pensar a cidade do futuro não a partir de perspectivas dualistas, mas colocando em relação dialógica a sensibilidade artística e a racionalidade técnica.

É certo que o pensamento urbanístico realizou distinções significativas quanto ao lugar ocupado pela cidade no tempo, a partir de atitudes modelares. A cidade como virtude (medieval) e como vício (moderna), situada entre um passado de trevas (a visão do Iluminismo) ou como traição de um passado áureo (a visão antiindustrial), são idéias que povoaram o imaginário da passagem do século XIX ao XX. O lugar da cidade nesse imaginário só poderia ser salvo por utopia ou projeto radical de volta ao passado ou de salto para o futuro, na reação à falta de nacionalismo da elite liberal cosmopolita e culta, conforme apontavam tanto as propostas de urbanistas, como a produção literária e artística. Não obstante, ainda nesta passagem de século, o pensamento sobre a cidade ainda se nutre de significados que reforçam as tensões, associando-as, tanto aos demônios da natureza humana, com todas as suas perversidades e contradições reais, como à idéia de cidades ideais, que seguem o modelo da "revelação" ou da "purificação".

Nas utopias urbanas contemporâneas, a cidade se transforma em um atributo atemporal, refutando as bases de cem anos atrás, em que se assentavam as experiências urbanas sem, no entanto, desvencilhar-se das ambigüidades então presentes naquele período. Recorrendo a Carl Schorske (2000:67), pode-se afirmar que se "a cidade moderna oferecia um hic et nunc eterno, cujo conteúdo era a transitoriedade, mas cuja transitoriedade era permanente", apresentando-se "como uma sucessão de momentos variegados, fugazes, e cada um deles deveria ser saboreado em sua passagem da inexistência ao esquecimento", nas tecnotopias pós-modernas essa transitoriedade é retomada como algo não apenas presente, mas desejável e algo inescapável.

É salutar que se tornem correntes, nesse início do século XXI, propostas pautadas por uma não-distinção entre cidade e natureza, que passam a ser interpretadas a partir de outros registros cognitivos, de outro vocabulário, em que comparecem os conceitos de entropia, co-evolução, bifurcação, instabilidade. Isso vem possibilitando a emergência de uma consciência que supera a contraposição entre aquilo que é natural, o que é humano e o que é tecnológico, respondendo à crescente demanda de complexidade, diante da qual não podemos mais reagir com respostas simplificadoras ou reducionismos incapazes de fornecer uma síntese unitária da realidade, concebida como equilíbrio instável. Assim, desenvolvimento da tecnologia, da natureza e da sociedade constituem elementos fundantes de um projeto de cidade de cidadãos, que necessita um olhar macroscópico, capaz de superar as disjunções entre lugar e não-lugar, territorialização e desterritorialização, natureza e cultura.

Por outro lado, escapando às formas tradicionais do pensamento, as fontes artísticas e literárias permitem não apenas captar a "imaginação poética", mas contribuem especialmente para a percepção do imaginário urbano em sentido amplo, isto é, os complexos processos e as múltiplas sociabilidades que a vida citadina apresenta. Em outros termos, se a imaginação poética difere da imaginação racionalista, isto ocorre, antes de tudo, porque a própria noção de espaço obedece a outras regras, distintas daquelas presentes no campo da instrumentalidade política. Ela é sensível à história dos diversos modos de mapear e representar o espaço de visão, perspectiva, plano e representação, convenções cartográficas, da simultaneidade do cubismo, das montagens cinemáticas, mas também dos diferentes modos da experiência subjetiva, em seus aspectos psíquicos, de projeção e introjeção.

$\mathrm{O}$ olhar do artista, longe de traduzir apenas imagens fragmentárias, revela "qualificações" do espaço urbano. Contrapondo-se, em alguns momentos, convergindo, em outros, com a interpretação de urbanistas e arquitetos, ${ }^{3}$ a cidade surge, para os artistas, como espaço de experiência polissensorial e dinâmica, a partir de estruturas denotativas de sua estrutura mental, cultural e física. Quem não reconhece a Paris moderna nas telas de pintores impressionistas como Manet, Monet, Renoir e outros? Ou São Petersburgo retratado nos textos de Dostoievski? Ou, ainda, a Paris de Baudelaire, Londres de Dickens? A Nova York de Woody Allen? Ou a São Paulo de Mário de Andrade e de Caio de Alcântara Machado?

A metrópole representada, evocada ou reinventada pelos artistas, literatos e cineastas desde o final do século XIX até nossos dias, suscita interpretações múltiplas e contraditórias, revelando as metamorfoses profundas, as ameaças da civilização urbana, os modos de apropriação material e simbólica, os elementos vitais do imaginário urbano, resultando em imagens paradigmáticas. Assim, o recurso à literatura, às artes plásticas e ao cinema permite um processo de compreensão que evidencia uma forte correspondência entre a produção cultural e as experiências e modos de subjetividade especificamente urbanos: a frag- 
mentação, a falta de profundidade, o caráter de dispersão, a instabilidade, a descontinuidade, a experiência do tempo como um presente perpétuo, de caráter espacial. Artistas, escritores e cineastas aparecem como portadores de um pensamento e um conhecimento que sintetizam, simultaneamente, uma realidade material e ideal. Sua atividade não pode ser reduzida à interpretação do espaço urbano a partir de elementos visuais ou traços mnemônicos e imaginários, mas deve ser inserida na complexidade da vida urbana como experiência produzida por uma necessidade: "o que a produz é a necessidade, para quem vive e opera no espaço, de representar para si de uma forma autêntica ou distorcida a situação espacial em que opera" (Argan, 1969:21). Em síntese, as artes realizam o que Jameson denomina "mapeamento cognitivo", ${ }^{4}$ expressando um desejo de totalidade, constituindo imagens capazes de fornecer um sentido de tempo e de lugar a partir do qual pode-se construir não apenas um sentido de orientação para movimentação no espaço da cidade, mas também formas de compreensão da realidade cultural e sociopolítica que esta representa.

Ao olhar as grandes cidades, chamam a nossa atenção o tráfego, as edificações, o movimento das pessoas, as diferentes combinações de informações e signos que permitem ao pensamento sociológico, político, econômico e cultural uma série de associações. Em nível mais profundo, temos de reconhecer que tais associações condensam um rigoroso espaço simbólico. Falamos em estar na cidade, em percebê-la e vivê-la não apenas porque vemos, ouvimos e sentimos, atribuindo significados a seus espaços, mas porque ela própria se converte em categoria do pensamento e da experiência.

Penso que arquitetos e planejadores tenham de se voltar às formas pelas quais os ambientes são criados e recriados, tanto em sua dimensão lógica quanto estética, inserindo suas preocupações na perspectiva da ética. Mas a cidade não pode ser pensada apenas como projeto, espaço produzido, conjunto finito de bens e funções visíveis, mas como um sistema aberto. Na visibilidade de seus processos de desenvolvimento devem ser percebidos os elementos intangíveis, os aspectos e lugares simbólicos da cultura que permitem a construção de cidades imagináveis. Quando nos debruçamos sobre a reserva de memória coletiva, povoada por descontinuidades, desejos, sonhos, abrimos caminho para alimentá-la quanto às prospectivas para o tempo que está por vir.

Torna-se urgente, nessa perspectiva, um enfrentamento dos desafios postos que também possibilite reencantar a consciência sociopolítica-cultural: há de se reconhecer as utopias, de modo a fazer frente ao criticismo doentio e ao ceticismo desabusado; sem resvalar no relativismo, buscar responder aos clichês dos discursos ético e político da mundialização, que asseguram uma imagem de mundo e das grandes metrópoles sob a aparência moral da homogeneização das culturas. Ética, estética e política devem e podem andar juntas para pensar o habitar ou o viver na cidade, desde que se desvencilhando das alternativas de modelização. Para isso torna-se condição necessária o reconhecimento da diferença, da singularidade e da universalidade, fazendo emergir o jogo das temporalidades e das incertezas presentes no contexto das metrópoles contemporâneas.

A metáfora do hipertexto, ${ }^{5}$ construída por Pierre Lévy para a compreensão da lógica que articula os elementos da comunicação, é válida, também, para todas as esferas da realidade em que as significações estejam em jogo e, portanto, para enriquecer nossa interpretação da cidade. Serve, principalmente, para sinalizar a possibilidade de saberes menos restritivos que, baseados em seus princípios, possam apontar um futuro promissor para as metrópoles contemporâneas.

Podemos ter esperanças para nossas cidades? O que, em particular, podemos delas esperar? Todos nós almejamos viver em lugar seguro, sem transtornos e felizes; entretanto, que essas esperanças possam vir a ser fundadas numa outra forma de pensar a cidade, não mais a partir de padrões normativos ideais, mas no alargamento da imaginação, que deve contribuir para a apropriação do tempo, do espaço, da vida e do desejo, de modo a introduzir o rigor na invenção e o conhecimento na utopia.

A arte, a técnica e a ciência, em perspectiva dialógica, podem contribuir para a constituição de procedimentos mentais capazes de apontar a emergência de modelos da realidade urbana, visando a restituir formas de sociabilidade pautadas pela apropriação e fruição de espaços e temporalidades múltiplas e reafirmando o direito à cidade como apelo, como exigência: "o direito à cidade não pode ser concebido como um direito de visita ou de retorno às cidades tradicionais. Só pode ser formulado como direito à vida urbana, transformada, renovada" (Lefebvre, 1991:116-17).

Se a cidade é um espaço simbólico no qual exercitamos nossa imaginação, penso ser possível que ela própria contribua com respostas criativas para a definição de nosso ethos: de "como estar 'em casa', num mundo no qual nossa identidade não é dada, nosso estar junto está em ques- 
tão, nosso destino é contingente e incerto: o mundo da violência de nossa própria auto-instituição" (Rajchmann, 1991).

A alma de São Paulo, com seus encantos entrópicos, que se expressam no desejo de seus habitantes, ${ }^{6}$ pode alimentar e conduzir a prospectivas para seu futuro:

São Paulo, 25 de janeiro de 2034, 17h:15m.

A conclusão do megaprojeto 2001 marca os 480 anos da cidade.

A comemoração dos 480 anos de São Paulo tem, hoje, um sabor especial. Multidões celebram em praças, ruas e avenidas a concretização do megaprojeto, iniciado no ano 2001, visando a melhoria das condições de vida e de renovação da cidade. Os conselhos comunitários das subprefeituras prepararam os festejos que acontecem em vários lugares: às margens dos Rios Tietê, Tamanduateí e Pinheiros, com águas limpas nas quais se pode novamente nadar, como há 100 anos, cujo projeto de urbanização se completou com a entrega dos parques que os ladeiam, abrigando uma série de atividades desportivas e culturais; no centro da cidade que, após a reabilitação de edifícios, trouxe de volta muitas pessoas que ali moram, trabalham e podem desfrutar dos prazeres de andar a pé para fazer compras, apreciar as artes plásticas, a música e as manifestações de grupos artísticos em completa segurança. Estes festejos acontecem, também, em todos os bairros, comemorando a implantação do sistema integrado de transportes que funciona por transmissão mista - térmica e elétrica - que, mesmo antes de ser completada, já vinha trazendo benefícios às populações locais, sendo mais baratas, reduzindo os níveis de poluição do ar e os ruídos. Finalmente, a metrópole saudável, equilibrada, responsável e cidadã, desejada por seus habitantes em 1999, está se tornando realidade...

\section{NOTAS}

E-mail da autora: margalimena@dglnet.com.br

1. Edward Relph desenvolveu o conceito de "imaginharia" como engenharia imaginativa da ilusão. É o mundo de Walt Disney, que capta o verdadeiro caráter da criatividade apoiada técnica e cientificamente, que subjaz às ilusões da Segunda Idade da Máquina. Embora mais concentrada em lugares como a Disneylândia, em produções televisivas e cenários de filmes, a imaginharia ultrapassa esses limites, constituindo a base para a construção de aldeias-museu cuidadosamente recriadas em seus pormenores, mas que omitem seus aspectos negativos. Exemplos disso são as réplicas de colônias americanas como Pilgrim Fathers, em Massachusetts, as Habitações Históricas para o Futuro, em Toronto e Kimberley, réplica de uma cidade de mineradores construída na Columbia Britânica. Confome Relph (1990).

2. Todas as referências a citações de Kolhaas foram extraídas de entrevistas concedidas aos jornais Público, Portugal, 02/04/1999 e El País, Espanha, 17/02/2001. Rem Kolhaas é, também, um dos organizadores do catálogo da Exposição Mutations e autor da obra Delirious New York, publicada pela Routledge, Nova York, 1991.

3. Este foi o tema de uma exposição realizada em Barcelona, entre junho e outubro de 1994, intitulada "Europa 1870-1993. Visiones urbanas. La ciudad del artista. La ciudad del arquitecto".

4. Conforme Jameson (1995:14). O autor constrói o conceito de mapeamento cognitivo reportando-se ao pós-modernismo, atribuindo-lhe uma função política, na medida em que considera a efetividade do aparato cultural do pós-modernismo como veículo de um novo tipo de hegemonia ideológica, por meio da exportação da lógica consumista norte-americana, bem como de seus produtos e valores culturais, pelos instrumentos da globalização. Tomo emprestado o conceito não como instrumento de despolitização, conforme o sentido atribuído pelo autor, mas como instrumento de politização, isto é, como elemento instaurativo de estratégias de representação e mapeamento da cidade, presentes nas formas e práticas urbanas.

5. Seis são os princípios que articulam a lógica hipertextual, segundo Lévy: os princípios da metamorfose, heterogeneidade, multiplicidade e escala, exterioridade, topologia e mobilidade dos centros, que levam à interpretação das imagens e paisagens de sentido. Conforme desenvolvido por Lévy (1990).

6. As fontes dessas "predições" são entrevistas com arquitetos, urbanistas, artistas e moradores de São Paulo publicadas em jornais e revistas, na passagem do anos 2000 e 2001. Conforme O Estado de S. Paulo, (30/12/1999 e 31/12/2000) e Revista Veja São Paulo, (22/01/2001).

\section{REFERÊNCIAS BIBLIOGRÁFICAS}

ARGAN, G.C. La storia dell'arte. Milão, Einaudi, n.1-2, 1969, p.21

DAVIS, M. Cidade de quartzo: escavando o futuro em Los Angeles. São Paulo, Ed. Página Aberta, 1993.

JACOBS, A. e APPLEYARD, D. "Touvard na urban design manifesto". In: LEGATES, R. e STOUT, R. The city reader. Nova York, Routledge, 1996.

JAMESON, F. Espaço e imagem. Teoria do pós-modernismo e outros ensaios Rio de Janeiro, Ed. UFRJ, 1995, p.14.

LEFEBVRE, H. O direito à cidade. São Paulo, Ed. Moraes, 1991.

LÉVY, P. L'intelligence collective. Paris, Éditions La Découvert, 1995, p.22.

. Les technologies d'intelligence. L'avenir de la pensée à l'ère informatique. Paris, Éditions La Découverte, 1990.

O ESTADO DE S. PAULO. "Como será a São Paulo de 2020”. 31/12/1999.

"A São Paulo que gostaríamos de ver" 31/12/2000.

RAJCHMANN, J. Truth and Eros. Foucault, Lacan and question of Ethics. Londres, Routledge, 1991.

RAMONET, I. Le monde sans route. Le monde diplomatique. Paris, out.1995 (suplemento).

RELPH, E. A paisagem urbana moderna. Lisboa, Edições 70, 1990.

SCANDURRA, E. "L'urbanistica: la disciplina 'moderna' a cultura contemporânea” Revista Pluriverso. Milão, n.2, 1998, p.92-103.

SCHORSKE, C. Pensando com a história. Indagações na passagem para o modernismo. São Paulo, Companhia das Letras, 2000.

SENNETT, R. Carne e Pedra. Rio de Janeiro, Ed. Record, 1997.

. The conscience of the eye. The design and social life of cities. Nova York, Norton, 1990. 